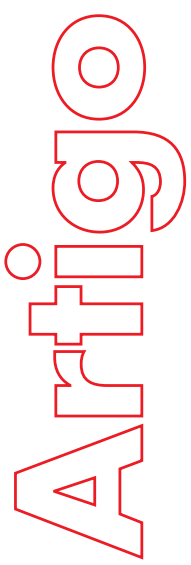

\section{Revista}

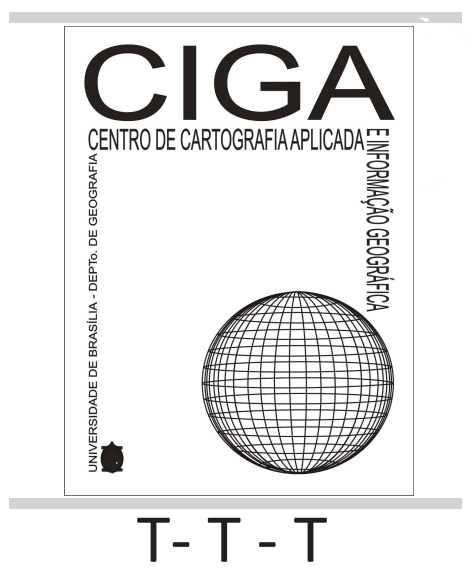

Revista Eletrônica: Tempo - Técnica - Território, V.11, N.1 (2020), 79:86 ISSN: 2177-4366

\section{A ABORDAGEM AFROBRASILEIRA NO LIVRO "GEOGRAFIA PARA Q ENSINO MEDIO"}

\section{Alexandre Ferreira da Silva}

p. $79-86$

Como citar este artigo:

Silva, A. F.

A ABORDAGEM AFROBRASILEIRA NO LIVRO "GEOGRAFIA PARA O

ENSINO MÉDIO" - Revista Eletrônica: Tempo - Técnica - Território, v.11, n.1 (2020),p.79:86 ISSN: 2177-4366.

Disponível em: http://periodicos.unb.br/index.php/ciga/

Este obra está licenciado com uma Licença Creative Commons Atribuição - Não Comercial 4.0 Internacional. 


\title{
A ABORDAGEM AFROBRASILEIRA NO LIVRO “GEOGRAFIA PARA O ENSINO MÉDIO”
}

\author{
Alexandre Ferreira da Silva \\ Graduando em Geografia pela Universidade de Brasília, Disciplina GEOAFRO - 1 Semestre 2019 \\ E-mail: afsalexandreferreira@gmail.com
}

RESUMO: A abordagem da ciência geográfica nas escolas é feita, em grande parte, a partir da utilização de livros didáticos, que apresentam diferentes temas em diferentes proporções. A proposta do presente trabalho é demonstrar e analisar como certos temas estão sendo tratados no livro de Demétrio Magnoli, especialmente aqueles relacionados às temáticas africana e afro-brasileira. Além disso, é feito um panorama geral sobre a abordagem geográfica, evidenciando as abordagens epistemológicas do autor e suas ponderações acerca dos assuntos.

Palavras-chave: Afro-brasileiro, geografia escola, ancestralidade.

ABSTRACT: Geography at school is shown, many times by books which presents different themes and proportions of its themes. The purpose of this paper is to demonstrate and make an analyse how specific matters are being addressed by Demétrio Magnoli, the author, especially those related to African and Afican-Brazilian topics. Moreover, a panoramic view of the geographical approach is done, making clear the epistemological choices by Magnoli and his considerations about the general topics.

Keywords: African-Brazilian, scholar geography, ancestry.

\section{INTRODUÇÃO}

O livro selecionado para a análise, intitulado "GEOGRAFIA PARA O ENSINO MÉDIO”, de Demétrio Magnoli (Magnoli, 2008), é direcionado, como o título sugere, para o ensino médio, sendo que abrange os conteúdos da ciência geográfica dos três anos do segmento.

Basicamente, a estruturação do livro é feita a partir de unidades que compreendem os capítulos (3 unidades em que se encontram 30 capítulos). Podemos observar, a partir da sumarização da obra que, a clássica fragmentação da geografia, sendo uma unidade dedicada aos conceitos físicos como, meio ambiente, clima e hidrografia; outra, a mais extensa, dedicada a parte humana e 
econômica, abarcando assuntos como globalização, blocos econômicos e comércio exterior; e ainda, uma terceira unidade, compreendendo o conteúdo geográfico do Brasil, onde podemos encontrar, de fato, a interface geográfica homem-natureza, tratando (e mesclando-as), por exemplo, características físicas do território associadas aos arranjos urbanos e/ou geopolítico.

No quadro a seguir, elaborado pelo autor deste trabalho, é possível observar as características básicas da obra.

QUADRO 1: INFORMAÇÕES SOBRE O LIVRO ANALISADO

\begin{tabular}{|l|}
\hline Nome da obra: GEOGRAFIA PARA O ENSINO MÉDIO. \\
\hline Autor: Demétrio Magnoli. \\
\hline Editora: Atual Editora. \\
\hline Número da edição: $1^{\text {a }}$ Edição. \\
\hline Ano de publicação: 2008. \\
\hline Cidade de publicação: São Paulo. \\
\hline Número de páginas: 576. \\
\hline
\end{tabular}

O principal objetivo da análise é observar como são tratados temas específicos, em especial àqueles que tratam do continente africano, das relações África-Brasil e das matrizes afro brasileiras presentes no território brasileiro. Ademais, o caráter epistemológico presente na obra também é abordado, sendo evidenciado as linhas geográficas seguidas por Magnoli, assim como suas influências e linhas de pensamento.

\section{CONCEPÇÕES INICIAIS E GERAIS DA OBRA}

Como na maioria dos livros didáticos, algumas informações iniciais são indicadas. No caso específico desta obra, não é diferente. Logo de início, na porção intitulada de “APRESENTAÇÃO”, podemos observar, entre outras características, a abordagem a ser utilizada pelo autor.

Invocando o geógrafo francês Jean Dresch (1905 - 1994), um dos precursores da Nova Geografia, através de uma de suas mais famosas expressões, Magnoli deixa bem claro seu ponto de vista e posicionamento 
“Chega de geografia sem drama!”, bradou certa vez o geógrafo e infatigável viajante francês Jean Dresch (1905-1994). A sua revolta é dirigida dirigia-se contra uma disciplina enfadonha, desinteressante, ensinada aos alunos como uma coleção de informações enciclopédicas desconectadas da vida e da experiência das pessoas. (MAGNOLI, 2008, p.3)

A partir da passagem acima, temos alguns indícios da linha a ser seguida, criticando o modelo atual, assim como fazia Dresch. Trata-se da crítica feita à Nova Geografia, aquela sem muitas reflexões e dotadas de quantificação, além dos resquícios deixados pela Escolas Geográficas Tradicionais, a Francesa e a Alemã. Nesse sentido, podemos inferir a epistemologia geográfica a ser adotada por Demétrio Magnoli, a crítica, dotada de reflexões, análises críticas e, sobretudo, drama.

Ainda nesta temática, característica ressaltada que merece destaque é a questão da parcialidade que (não) será adotada, ou como utiliza o próprio autor, doutrinação. Uma crítica dramática dotada de fatos e análises, sem qualquer forma de linguagem ou artifício doutrinador. Geografia com drama, mas destituída de doutrinação, uma interpretação pluralista do mundo e do Brasil. Essas são as contribuições que esta obra pretende oferecer a professores criativos e estudantes cidadãos (MAGNOLI, 2008). Visto que, o livro é direcionado para jovens adolescentes, ainda estabelecendo suas visões de mundo e ideologias, a imparcialidade e a não-doutrinação se faz essencial. A falta dela, numa ciência humana-social, dotada de pragmatismo e diferentes interpretações pode exercer um caráter manipulatório e influenciador na vida dos estudantes.

Evoluindo nos conceitos apresentados pelo autor, chegamos ao conceito de Espaço, localizado na unidade inicial, intitulada de “Meio Natural e Espaço Geográfico" é vista a definição de espaço geográfico. Tratada de forma breve e sintética, é encontrada de forma explícita no livro. A decisão de sintetizar o termo é interessante, visto o grau de sua complexidade. A abstração do da definição de espaço geográfico pode ser um fator decisivo para o entendimento do conceito, logo, a sintetização se dá de caráter estratégico e funcional para as demandas do segmento escolar

A geografia é uma ciência humana. Ela estuda o espaço geográfico, ou seja, o espaço produzido pela intervenção das sociedades sobre a superfície da Terra. Contudo, essa superfície física existe antes e independente da presença humana. Além disso, ela não é um palco fixo sobre o qual agem as sociedades, mas um meio natural complexo, em permanente mudança. (MAGNOLI, 2008, p.8)

Nesse sentido, vemos que a intervenção antrópica na superfície terrestre produz o espaço geográfico, o que nos remete a similaridades trazidas por Milton Santos em sua obra, em termos como espaço utilizado. 


\section{TRATATIVAS ÉTNICO-RACIAIS}

Trazendo à tona as questões étnico-raciais, sobretudo no contexto brasileiro, o autor dedica um capítulo para esta temática, trata-se do capítulo 9 (Brasil, Estado e Espaço Geográfico). Localizado na segunda unidade, que trata aspectos brasileiros, há uma explanação acerca da formação da sociedade brasileira e seus principais grupos componentes.

São definidos três grupos principais formadores da sociedade brasileira: brancos, africanos (e seus descendentes) e os povos da floresta. Mais do que isso, são trazidas abordagens históricas da formação atual da sociedade brasileira, demonstrando os efeitos do sistema escravista e do genocídio dos povos nativos.

A estrutura colonial do Estado Brasileiro é denunciada pelo autor, trazendo a Lei Áurea como uma das maiores derrotas políticas dos interesses da aristocracia brasileira, frente à Inglaterra, potência hegemônica da época, que historicamente possui forte caráter abolicionista.

Através do ponto de partida da formação da sociedade brasileira, reflexões demográficas são feitas, principalmente através de gráficos, tabelas e mapas. Reflexões que evidenciam a distribuição da população pela cor da pele nas regiões do Brasil. Ao tecer suas ponderações acerca do tema, são evidenciadas políticas governamentais de embranquecimento da população, propiciada através de inúmeros incentivos a imigrantes europeus, na tentativa de apagar, ou ao menos, diminuir as heranças do sistema escravista, que permaneceu vigente por quase 4 séculos no Brasil.

A América portuguesa originou um Estado unificado. A América espanhola fragmentou-se em diversos Estados. A unidade do Brasil repousa no Império e no instituto da escravidão, que unificou os interesses das elites regionais. A República e a federação foram criadas sobre os escombros do Império, mas refletem o desenho administrativo das capitanias coloniais.” (MAGNOLI, 2008, p.168)

“A distribuição geográfica dos grupos por cor da pele oferece pistas sobre a formação social do país. O predomínio de pardos e a parcela expressiva de pretos no Nordeste é um indício do peso numérico dos escravos na estrutura produtiva regional nos tempos coloniais. No Norte, o predomínio de pardos está ligado essencialmente ao processo de miscigenação com a população indígena original. No Sudeste e no Sul, as correntes de imigração europeia, nos séculos XIX e XX, contribuem para explicar o predomínio dos brancos.” (MAGNOLI, 2008, p.169-170)

Ainda na composição da população brasileira, comunidades tradicionais são lembradas, em especial às comunidades quilombolas, e povos nativos, ambos remanescentes das investidas de dizimação pelo homem branco, num passado recente, contrastando com as atuais políticas de amparo jurídico, institucional e constitucional. 
Na questão indígena são trazidos marcos para esses povos, como a criação do Sistema de Proteção ao Índio (SPI), em 1910, e sua substituição pela ainda vigente, Fundação Nacional do Índio (Funai), de 1967. Sem dúvidas os artifícios reparadores pelo Estado brasileiro ganham destaque na explanação de Magnoli.

No Brasil, ao contrário do que aconteceu nos Estados Unidos, desde a Abolição não se fizeram leis segregacionistas e, com a Lei Afonso Arinos, de 1951, a prática de racismo foi qualificada como crime. A igualdade política e jurídica convive, contudo, com a herança da escravidão. Os ex-escravos não receberam terras para trabalhar e, sem recursos ou instrução, incorporam-se em condição desvantajosa ao mercado de compra e venda de força de trabalho. A pobreza atinge, desproporcionalmente, a população classificada como "preta" e "parda". Esses segmentos da população têm, em média, menor escolaridade e rendimentos familiares mais baixos. (MAGNOLI, 2008, p.175)

\section{O SISTEMA ESCRAVISTA E AS RESISTÊNCIAS}

O Brasil é, sem dúvidas, o país que mais recebeu escravos africanos, sobretudo de países africanos onde os portugueses possuíam uma forte influência. Magnoli aborda essa temática em dois momentos diferentes, hora no capítulo 9 e mais à frente no capítulo 30 intitulado Unidade $e$ Diversidade na África, único capítulo dedicado exclusivamente ao continente africano

A dinâmica da diáspora africana para o Brasil é abordada brevemente. São mostrados os principais locais de origem desses povos, que foram trazidos para o Novo Mundo forçadamente. Além da perspectiva traumática de sofrimento vivida por estes povos durante a diáspora, é nos lembrado as características culturais advindas juntamente com eles, que logo seriam fortemente discriminadas pelo europeu colonizador.

Por mais de três séculos, a América portuguesa e, depois, o Brasil exploraram o trabalho escravo. Entre 1551, início do período escravagista, e 1850, ano em que o tráfico escravo foi finalmente proibido pela Lei Eusébio de Queirós, pouco mais de 4 milhões de africanos chegaram aos portos brasileiros nos navios negreiros, para trabalhar nas plantações açucareiras, nas minas de ouro, nas fazendas de café e nas residências dos colonos. (MAGNOLI, 2008, p.172)

Os cativos provinham de diversos lugares da África e falavam diferentes línguas maternas. Deslocados à força, separados de sua terra e sua gente, tinham parcos meios meios para resistir. Mas resistiram todo o tempo, criando ritmos e elaborando rituais, ou seja, produzindo cultura. (MAGNOLI, 2008, p.172)

Já no capítulo 30, o sistema escravista é tratado numa perspectiva diferente. São evidenciados quesitos demográficos, econômicos e sociais. A grande diáspora, não refletiu somente na reorganização da colônia, e posteriormente no Brasil, mas também no continente africano. 
O tráfico de escravos africanos foi conduzido inicialmente pelos árabes, mas experimentou vigoroso crescimento a partir do século XVI, quando passou a abastecer de mão de obra as colônias europeias na América. Até meados do século XIX, quando se extinguiu o tráfico, cerca de 15 milhões de africanos foram capturados e transferidos por negociantes árabes ou europeus. As vítimas, em sua maioria, eram jovens do sexo masculino. (MAGNOLI, 2008, p.541)

Do ponto de vista social, o comércio de escravos desestruturou famílias, clãs e reinos. Do ponto de vista demográfico, provocou uma verdadeira sangria, cujo efeito está registrado no gráfico abaixo: entre 1650 e 1850, a população do continente permaneceu praticamente estagnada. (MAGNOLI, 2008, p.541)

A dinâmica do tráfico, desde a captura dos escravos até seu desembarque em terras americanas também é demonstrado por Magnoli, algumas características são ressaltadas

Os traficantes raramente se aventuravam se aventuravam na captura de negros no interior da África. Como regra, os africanos eram capturados por outros africanos, para ser vendidos nos portos aos grandes traficantes exportadores. (MAGNOLI, 2008, p.541)

O negócio do tráfico desenvolveu tentáculos e ramificações nas sociedades africanas, tornando-se uma fonte extraordinária para chefias de reinos e clãs que se dedicavam à captura. Formaram-se reinos negreiros, que se envolviam em conflitos pelo controle das zonas de captura e rotas de tráfico. Esses reinos especializavam-se na captura de gente, em particular de inimigos derrotados, organizando expedições de captura e o transporte dos cativos aos portos. (MAGNOLI, 2008, p.541)

\section{REPRESENTAÇÕES AFRO BRASILEIRAS E SUAS REALIDADES}

Ao apresentar imagens e ilustrações que demonstram a realidade de matrizes africanas no Brasil contemporâneo, nota-se um certo cuidado por parte do autor, evitando os comuns estereótipos encontrados em imagens e contextos envolvendo o continente africano e seu povo (juntamente a seus descendentes). Vemos imagens de Quilombos e Terreiros de Candomblé, ressaltando suas características reais, não ressaltando aspectos negativos, como comumente observamos em diferentes abordagens.

Ainda sim, este “cuidado” não se dá com totalidade, contendo diferentes imagens que reforçam o estereótipo do continente africano, ilustrando sofrimento, miséria e catástrofes. Não há, de fato, imagens que retratem os grandes centros urbanos africanos, como Cairo, Luanda, Cidade do Cabo ou Nairóbi, o que se encontra são imagens retratando campos de refugiados, guerrilhas, terrorismo e golpes de Estado.

Demonstrando a realidade atual de afrodescendentes brasileiros, observamos gráficos e mapas do tema. Importante ressaltar que, sempre que são apresentado esses gráficos e/ou mapas, há uma reflexão por parte do autor acompanhando a ilustração, tecendo considerações crítico-técnicas. 
Podemos observar a natureza dessas considerações a seguir, que precedem ou aparecem logo após às ilustrações

Essa herança transparece nas estatísticas atuais. A incidência da pobreza da pobreza é maior entre os que se declaram pardos e pretos do que entre os que se declaram brancos. Dos 57 milhões de brasileiros que, em 2004, viviam abaixo da linha da pobreza, 34 milhões definiam-se como pardos. (MAGNOLI, 2008, p.305)

As diferenças traduzem-se nos mais diversos indicadores. Em 2004, os brancos tinham rendimentos médios de 3,8 salários mínimos, contra 2,1 salários mínimos entre os pretos e 2 entre os pardos. O número médio de anos de estudo dos brancos era de 8,4, contra 6,4 entre os pretos e 6,2 entre os pardos. (MAGNOLI, 2008, p.305)

O peso das desigualdades regionais pode ser observado nos mapas a seguir. Os brancos predominam entre os mais ricos (população com renda familiar de dez salários mínimos ou mais) e também entre os mais pobres (população com renda familiar inferior três salários mínimos) na maior parte do Sudeste e do Sul, regiões onde constituem a maioria da população. Inversamente, os pardos predominam entre os mais ricos e também entre os mais pobres no Nordeste e no Norte, regiões onde constituem a maioria da população. (MAGNOLI, 2008, p.306)

\section{CONSIDERAÇÕES FINAIS}

Há, de fato, uma conscientização por parte do autor, das desigualdades existentes entre afrodescendentes e brancos no Brasil, na qual Magnoli culpa, principalmente, o sistema escravista que permaneceu vigente por mais três séculos. Ainda nesta temática, conclusões regionais são tomadas, associando a pobreza à cor da pele, na qual regiões com maior número de pardos e negros apresentam níveis mais elevados de pobreza. Infelizmente, não há na obra informações acerca da situação política de pardos e negros.

Cerca de 74\% dos brancos vivem no Sudeste e no Sul, as regiões mais ricas do país, enquanto $52 \%$ dos pardos e pretos vivem no Nordeste e no Norte, as regiões mais pobres. Essa distribuição regional da população por cor da pele é um fator decisivo para se compreender os padrões de incidência da pobreza. (MAGNOLI, 2008, p.306)

Ainda que de forma superficial, o autor reconhece as referências afro-brasileiras como verdadeiros componentes formadores da sociedade brasileira atual, ainda que podemos constatar um caráter bastante simplório no tema. É possível ver apenas um tangenciamento acerca destes temas. Ainda que podemos encontrar imagens positivas, sem qualquer tipo de estereótipo, ainda há muitas que o fazem, perpetuando a problemática visão eurocêntrica. 
Tratando-se exclusivamente das matrizes afro-brasileiras, observamos apenas imagens seguidas por notas de rodapé, sem qualquer reflexão profunda acerca do tema, o que, acima de tudo, prejudica a alfabetização ancestral de jovens brasileiros(as).

Sem dúvidas, uma reestruturação de livros didáticos é necessária, a lógica europeia e norteamericana ainda dominam as visões escolares brasileiras. A critério de exemplos, é possível observar capítulos exclusivos para países, como é o caso dos Estados Unidos (capítulo 22), Japão (capítulo 25) e Índia (capítulo 27), enquanto que para todo o continente africano, há apenas um.

É inegável que a obra “Geografia para o Ensino Médio”, de Demétrio Magnoli, necessita de maior espaço dedicado a temáticas afro-brasileiras, ressaltando sua importância e necessidade para a formação do povo brasileiro e do país Brasil. Sem dúvidas, a educação é um dos principais meios para a conscientização do povo brasileiro de suas ancestralidades. Mudanças de abordagem das temáticas negras na educação brasileira, sem dúvidas, iriam causar inflexões nas conturbadas e problemáticas relações étnico-sociais presentes no Brasil.

\section{REFERÊNCIAS BIBLIOGRÁFICAS}

MAGNOLI, Demétrio. Geografia para o ensino médio. São Paulo: Atual, 2008. 